\title{
Critical soil bulk density for soybean growth in Oxisols
}

\author{
Michel Keisuke Sato, Herdjania Veras de Lima, Pedro Daniel de Oliveira, and Sueli Rodrigues* \\ Agricultural Sciences Institute, Federal Rural University of Amazon, Belem, Perimetral Avenue, 2501, \\ Zip code 66077-901, Para, Brazil
}

Received January 29, 2015; accepted September 3, 2015

\begin{abstract}
A b s tra ct. The aim of this study was to evaluate the critical soil bulk density from the soil penetration resistance measurements for soybean root growth in Brazilian Amazon Oxisols. The experiment was carried out in a greenhouse using disturbed soil samples collected from the northwest of Para characterized by different texture. The treatments consisted of a range of soil bulk densities for each soil textural class. Three pots were used for soybean growth of and two for the soil penetration resistance curve. From the fitted model, the critical soil bulk density was determined considering the penetration resistance values of 2 and $3 \mathrm{MPa}$. After sixty days, plants were cut and root length, dry mass of root, and dry mass of shoots were determined. At higher bulk densities, the increase in soil water content decreased the penetration resistance, allowing unrestricted growth of soybean roots. Regardless of soil texture, the penetration resistance of 2 and $3 \mathrm{MPa}$ had a slight effect on root growth in soil moisture at field capacity and a reduction of $50 \%$ in the soybean root growth was achieved at critical soil bulk density of $1.82,1.75,1.51$, and $1.45 \mathrm{Mg} \mathrm{m}^{-3}$ for the sandy loam, sandy clay loam, clayey, and very clayey soil.

$\mathrm{K}$ e y w o r d s: soil compaction, soil penetration resistance, soil texture, Glycine max L.
\end{abstract}

\section{INTRODUCTION}

The soybean (Glycine max L.) has been highlighted as the main crop responsible for the advance of the agricultural frontier in the Amazon region with a significant increase in the cultivated area in this region. An example is the State of Para, where the area with cultivated soybean increased from 2650 ha in 2000 to 120000 ha in 2012. Estimates indicate that the Northeast Para has a potential of nearly two million hectares for cropping soybean. However, the predominant soil management in the region is the conven-

*Corresponding author e-mail: rodsueli@gmail.com tional tillage system with regular ploughing and disking. The use of conservation management practices, such as conservation tillage, is still limited in the region.

Therefore, the perspective that this scenario contributes to adverse changes in the landscape, mainly related to soil degradation, specifically soil compaction, is becoming a concern. The yield perspectives can also be affected since the agricultural production potential is determined by factors related to soil and crop.

Soil cultivation with intensive use of machinery on bare soil is the primary agent of soil degradation, causing erosion and compaction. Among the soil compaction effects, there are an increase in bulk density and soil penetration resistance and a decrease in porosity and soil air permeability (Koolen, 1994). Soil bulk density is one of the most frequent soil physical indicators to evaluate soil compaction, and changes in this soil attribute can influence crop yield. Usually the relationship between bulk density and crop yield is parabolic with a maximum bulk density that depends on soil texture, crop, and climate (Czyż, 2004; Pabin et al., 1991).

The soil bulk density from which the soil strength becomes so high that it reduces or prevents root growth is denominated critical bulk density (Reichert et al., 2009), and its value depends mainly on soil textural class. Reichert et al. (2003) proposed critical bulk density for some textural classes: $1.30-1.40,1.40-1.50$ and $1.70-1.80 \mathrm{Mg} \mathrm{m}^{-3}$ for: clayey soils, clay loam soils, and sandy loam soils, respectively. However, some crops may grow even in compacted soils, depending on the plant characteristics (Rosolem et $a l ., 2002$ ), and knowledge of these differences may support crop selection or soil management practices.

(C) 2015 Institute of Agrophysics, Polish Academy of Sciences 
In Brazil, numerous studies have shown that crops is affected by soil compaction, resulting from land use practices (da Veiga et al., 2007; Reichert et al., 2009; Seben Junior et al., 2014; Suzuki et al., 2013). However, these studies were performed in regions with weather conditions very different from the Amazon region, where information is still quite scarce. In this region, there has been no research trying to identify reference values for soil physical properties. In this work, we consider the possible effects of the increase in soil bulk density for soils located in a different climatic condition. This information may help to plan sustainable soil management practices combining high production and environmental conservation. Thus, the aim of this study was to evaluate the critical soil bulk density, from the soil penetration resistance, for soybean root growth in Brazilian Amazon Oxisols with different textures.

\section{MATERIAL AND METHODS}

The experiment was carried out in a greenhouse, from July to September 2011, at the Institute of Agricultural Sciences at the Federal Rural University of Amazon (UFRA), in Para, Brazil.

Disturbed soil samples were collected from four areas in two counties in the northwest of Para, which represents the main region of soybean production in this state. In all areas, the soils were classified as Oxisols (Embrapa, 2006). A heterogeneous set of soil clay content typical of the region was also selected. The soil particle size analysis performed with the pipette method (Gee and Bauder, 1986) is shown in Table 1.

Approximately $400 \mathrm{~kg}$ of soil from $0-0.20 \mathrm{~m}$ depth were collected in each area at 10 points to gather a composite sample. The soil samples were air-dried and sieved $(2 \mathrm{~mm})$. Subsamples were used for fertility analysis according to procedures described by Embrapa (2011). The fertility analysis (Oliveira et al., 2015) showed that the soil was limed and fertilized according to the soybean crop requirements (Embrapa, 2010).

As treatments, different levels of soil bulk density $(B D)$ were defined for each soil textural class. From the bulk density considered optimal for each soil, it was gradually increased by about $0.1 \mathrm{Mg} \mathrm{m}^{-3}$ unit. Next, five $B D$ levels were defined for the sandy loam and sandy clay loam soils $\left(1.35,1.40,1.50,1.60\right.$, and $\left.1.70 \mathrm{Mg} \mathrm{m}^{-3}\right)$ and three for the clayey $\left(1.35,1.40\right.$ and $\left.1.50 \mathrm{Mg} \mathrm{m}^{-3}\right)$ and very clayey soils $\left(1.15,1.24\right.$, and $\left.1.30 \mathrm{Mg} \mathrm{m}^{-3}\right)$. Only three levels were defined for the clayey soils because it was not possible to compact them above the latter limit.

A completely randomized experiment was designed with five replicates $(\mathrm{N}=80)$. Eighty cylinders of PVC $(0.20 \mathrm{~m}$ high, $0.23 \mathrm{~m}$ in diameter) with perforated bottoms were filled with slightly moist, ie ca. $10 \%$, soil to facilitate the compaction process. The soil samples were placed into the cylinders up to $0.20 \mathrm{~m}$ height and manually compressed with a $7 \mathrm{~kg}$ rammer in about $2 \mathrm{~cm}$ deep layers, to assure bulk density homogeneity. After the addition of each layer, the soil surface was slightly scratched for addition of the next layer in order to improve contact and prevent the formation of distinct layers. Additional details about the soil compaction methodology in the pots are provided by Oliveira et al. (2015).

Three of the five pots were used for soybean seeding $(\mathrm{N}=48)$ and two to collect undisturbed samples ( $\mathrm{N}=32)$. In the pots designated for sampling, four samples were taken using cylindrical steel rings with dimensions of $0.05 \mathrm{~m}$ height and diameter, totalling 128 undisturbed samples. These samples were saturated, grouped $(\mathrm{N}=16)$ and then brought to equilibrium on the following matric potentials $(\Psi):-0.003 ;-0.006 ;-0.01 \mathrm{MPa}$ using table tension and $-0.03 ;-0.06 ;-0.1 ;-0.3 ;-0.6 \mathrm{MPa}$ in Richards chambers (Klute, 1986). The soil water content at $-0.01 \mathrm{MPa} \Psi$ was defined as the water content at field capacity $\left(\theta_{F C}\right)$.

After reaching the equilibrium at each potential, the samples were weighed and the soil penetration resistance $(P R)$ was determined using an electronic penetrometer similar to that described by Figueiredo et al. (2011) with a $30^{\circ}$ cone and base area of $0.1256 \mathrm{~cm}^{2}$. The device was settled to register a reading every one second. The readings corresponding to $5 \mathrm{~mm}$ on the top and bottom were eliminated and an average was calculated for each sample. Finally, the samples were oven-dried at $105^{\circ} \mathrm{C}$ for $48 \mathrm{~h}$ for determination of $B D$ and soil water content $(\theta)$ at each $\Psi$ (Blake and Hartge, 1986).

T a b l e 1. Results for particle size analysis for the soils sampled in two counties in Para state, north Brazil

\begin{tabular}{llcccc}
\hline & & Sand & Silt & Clay & Organic matter \\
\cline { 3 - 6 } Soil sampling site & Texture & \multicolumn{2}{c}{$\left(\mathrm{g} \mathrm{kg}^{-1}\right)$} \\
Capitão Poço & Sandy loam & 756.2 & 48.7 & 195.1 & 25.80 \\
Paragominas & Sandy clay loam & 663.3 & 110.0 & 226.7 & 37.13 \\
Capitão Poço & Clayey & 396.8 & 97.2 & 506.0 & 27.34 \\
Paragominas & Very clayey & 53.2 & 216.5 & 730.3 & 43.43 \\
\hline
\end{tabular}

Sand $=2-0.05 \mathrm{~mm}$, silt $=0.05-0.002 \mathrm{~mm}$, clay $<0.002 \mathrm{~mm}$. 
For each soil, the $P R$ results were adjusted in relation to the $\theta$ and $B D$ using the non-linear model proposed by Busscher (1990):

$$
P R=a \theta^{b} B D^{c},
$$

where: $P R$ is the soil penetration resistance (MPa), $\theta$ the volumetric soil water content $\left(\mathrm{m}^{3} \mathrm{~m}^{-3}\right), B D$ is the soil bulk density $\left(\mathrm{Mg} \mathrm{m}^{-3}\right)$ and $a, b$ and $c$ are the model parameters.

From the model parameters, using the same equation, the critical soil bulk density $(B D)$ was determined for the whole range of soil water content obtained from the matric potentials, considering the $P R$ values suggested as critical for plant root growth: 2.0 MPa (Taylor, 1966) and 3.0 MPa (Horn and Baumgartl, 2000).

In the other three pots for each soil and $B D$, four soybean seeds of the cultivar BRS 'Sambaíba' were seeded at a depth of $0.015 \mathrm{~m}$. After emergence, thinning was done leaving two seedlings per pot. Soils were kept at field capacity (soil water content at $-0.01 \mathrm{MPa}$ ) by daily weighing and water addition using a watering can until reaching the desired weight in each pot.

Sixty days after emergence, in the R2 or blister stage (flowering), the plants were cut and the root system separated and washed with abundant water using a sieve $(5 \mathrm{~mm})$ as support. Root length (RL) according to Tennant (1975) and the dry mass of roots (DMR) after oven-drying at $60^{\circ} \mathrm{C}$ for $72 \mathrm{~h}$ were determined. Since the aim of this study was not to quantify the variables of soybean root growth, but to identify the $B D$ values at which soybean root growth is severely limited, the data were transformed into relative values by dividing the maximum value obtained for RL and DMR by its values observed in each treatment $(B D)$. The purpose was a clearer understanding of soybean root response to different levels of $B D$. The shoots were also oven-dried at $60^{\circ} \mathrm{C}$ for $48 \mathrm{~h}$ and weighed (dry mass of shoot $=$ DMS) and related to DMR to assess if the above-ground part of the plants were affected by restrictive root growth.
The data analysis was performed using SAS (Statistical Analysis System, version 9.2). For the adjustment of the soil penetration resistance curve, the PROC NLIN was used. We analyzed the variance for RL and DMR data and, when significant, regression analysis between $B D$ and the soybean growth variables was performed.

\section{RESULTS AND DISCUSSION}

The nonlinear model (Busscher, 1990) was highly significant $(\mathrm{p}<0.001)$ and appropriate for the data distribution for all soil textural classes (Table 1). The model parameters explained $>80 \%$ of the variability of $P R$ as a function of $\theta$ and $B D$. Regardless of the soil textural class, the negative relation between $P R$ and the soil water content $(\theta)$ and the positive relation to the soil bulk density $(B D)$ were verified. This relation has already been reported and justified in several studies, which reported that the decrease in soil water content increases the cohesive forces among soil particles, especially with an increment in $B D$ (Bengough and Mullins, 1990, Weber and Biskupski, 2008).

In Table 2 , the $B D$ and respective $\theta_{F C}$ for each soil are presented. Considering the soil water content $\left(\theta_{F C}\right)$, it was observed that, for the sandy loam, the $P R$ was critical (> $2 \mathrm{MPa}$ )only for the higher $B D$, at $1.70 \mathrm{Mg} \mathrm{m}^{-3}$ the $P R$ was $3.48 \mathrm{MPa}$. For the sandy clay loam, the soil exhibited limitation due the high strength of $B D$ of $1.6 \mathrm{Mg} \mathrm{m}^{-3}$ $(2.13 \mathrm{MPa})$. At the lowest $B D$, the clayey soil at $\theta_{F C}$ reached a $P R$ value of $2.38 \mathrm{MPa}$, which was reduced at $B D$ of $1.4 \mathrm{Mg} \mathrm{m}^{-3}(1.66 \mathrm{MPa})$ and increased again at the highest $B D(2.30 \mathrm{MPa})$. For the very clayey soil, only the lowest $B D$ exhibited $P R<2 \mathrm{MPa}$. In this soil, the $B D$ of $1.30 \mathrm{Mg}$ $\mathrm{m}^{-3}$ reached a $P R$ of $2.56 \mathrm{MPa}$, even with high soil water content $\left(0.494 \mathrm{~m}^{3} \mathrm{~m}^{-3}\right)$.

The higher the clay content, the higher the $P R$, as can be verified by the equations in Table 2 . According to the equations, considering the same $\theta$ and $B D, P R$ increases

T a b l e 2. Soil bulk density $(B D)$ treatments and water content at field capacity $\left(\theta_{F C}\right)$ for each soil and equations for the soil penetration resistance curve using a non-linear model (Busscher, 1990) for the evaluated soils

\begin{tabular}{|c|c|c|c|c|c|c|c|c|c|}
\hline \multicolumn{4}{|l|}{ Soil } & \multicolumn{3}{|c|}{ Treatment } & \multirow{2}{*}{$\begin{array}{l}\text { Equation } \\
P R=0.0053 \theta^{-1.276} B D^{8.910}\end{array}$} & \multirow{2}{*}{$\frac{\mathrm{R}^{2}}{0.92}$} & \multirow{2}{*}{$\frac{F}{386.9^{\prime}}$} \\
\hline Sandv loam & $B D$ & 1.35 & 1.40 & 1.50 & 1.60 & 1.70 & & & \\
\hline Salluy I Uantu & $\theta_{F C}$ & 0.307 & 0.299 & 0.393 & 0.303 & 0.252 & & & \\
\hline \multirow{2}{*}{$\begin{array}{l}\text { Sandy clay } \\
\text { loam }\end{array}$} & $B D$ & 1.35 & 1.40 & 1.50 & 1.60 & 1.70 & $P R=0.0377 \theta^{-0.824} B D^{7.244}$ & 0.83 & $179.4^{*}$ \\
\hline & $\theta_{F C}$ & 0.371 & 0.463 & 0.443 & 0.466 & 0.465 & & & \\
\hline \multirow{2}{*}{ Clayey } & $B D$ & 1.35 & 1.40 & 1.50 & & & $P R=0.0553 \theta^{-2.348} B D^{4.005}$ & 0.95 & $397.3^{*}$ \\
\hline & $\theta_{F C}$ & 0.336 & 0.417 & 0.408 & & & & & \\
\hline \multirow{2}{*}{ Very clayey } & $B D$ & 1.15 & 1.24 & 1.30 & & & $P R=0.0103 \theta^{5.485} B D^{6.275}$ & 0.97 & $713.8^{*}$ \\
\hline & $\theta_{F C}$ & 0.461 & 0.481 & 0.494 & & & & & \\
\hline
\end{tabular}

$B D$ - soil bulk density $\left(\mathrm{Mg} \mathrm{m}^{-3}\right), \theta_{F C}-$ soil water content at field capacity $\left(\mathrm{m}^{3} \mathrm{~m}^{-3}\right)$. Significant at a $0.1 \%$ probability level $(\mathrm{p}<0.001)$. 

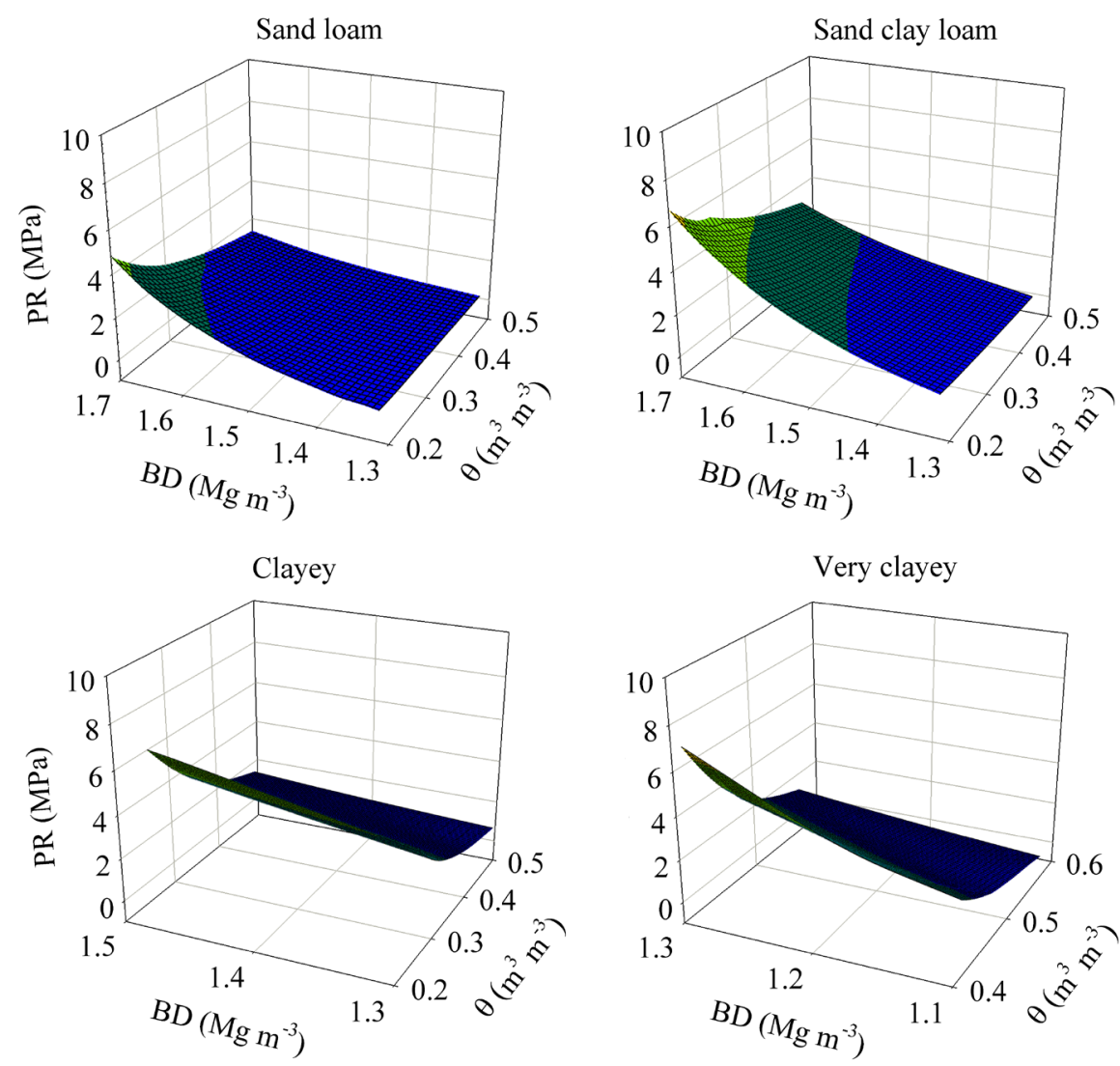

Fig. 1. Soil penetration resistance $(P R)$ as a function of bulk density $(B D)$ and soil water content $(\theta)$ for the evaluated soil textural classes.

substantially with the increasing clay content. Figure 1 shows that more clayey soils have higher $P R$ values even for higher $\theta$ and lower $B D$. This behaviour is due to the higher clay content resulting in higher friction and cohesion among the soil particles, causing the increase in $P R$ (Tormena et al., 2008). Hence, soils with high clay content can reach $P R$ values restrictive to plant growth sooner, with variations in $\theta$ or $B D$, compared with sandier soils.

The $B D$ is a value in which the soil strength becomes so high that it reduces or prevents root growth (Rosemberg, 1964). The higher the $B D$, regardless of the soil texture and $P R$, the higher the soil water content (Fig. 2).This means that, when there is enough water available in the soil, it only imposes physical constraints to root growth, i.e. high penetration resistance, at high values of $B D$. In the very clayey soil (Fig. $2 \mathrm{~d}$ ), in conditions of lower $\theta$ $\left(<0.40 \mathrm{~m}^{3} \mathrm{~m}^{-3}\right)$, soil imposes restrictions to root development at very low $B D\left(B D<1.0 \mathrm{Mg} \mathrm{m}^{-3}\right)$. This $B D$ range can be extended (Fig. 2) if the critical $P R$ value of $3 \mathrm{MPa}$ suggested by Horn and Baumgartl (2000) is considered. Thus, it is possible to establish a $B D$ range from which the $P R$ restricts root growth, taking into account the variation of $\theta$.

Considering the soil water content at field capacity $\left(\theta_{F C}\right)$ and adopting the $P R$ value of $2 \mathrm{MPa}$ as critical, from the equations in Table 2 , the $B D$ were $1.65,1.50,1.35$, and $1.22 \mathrm{Mg} \mathrm{m}^{-3}$ for the sandy loam, sandy clay loam, clayey, and very clayey soils, respectively. However, if we take the $P R$ value of $3 \mathrm{MPa}$, these values are elevated to $1.73,1.59$, 1.50 , and $1.30 \mathrm{Mg} \mathrm{m}^{-3}$. According to Tormena et al. (2008), the $B D$ depends mainly on the soil particle size distribution. The high clay content of the very clayey soil gives it greater cohesion among particles, imposing constraints to root development at $B D$ values much lower than for the

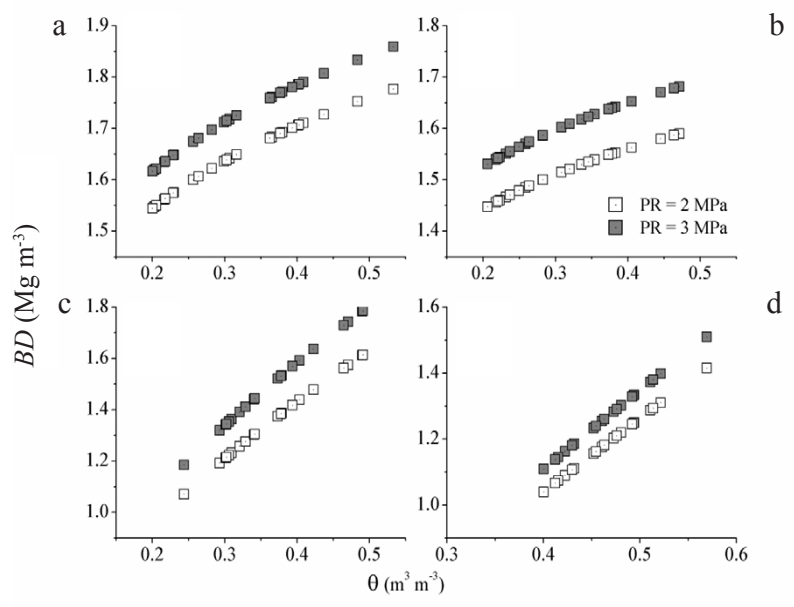

Fig. 2. Variation of critical bulk density $(B D)$ related to soil water content $(\theta)$ in: $\mathrm{a}$ - sandy loam, b - sandy clay loam, c - clayey, and $\mathrm{d}$ - very clayey soils. 


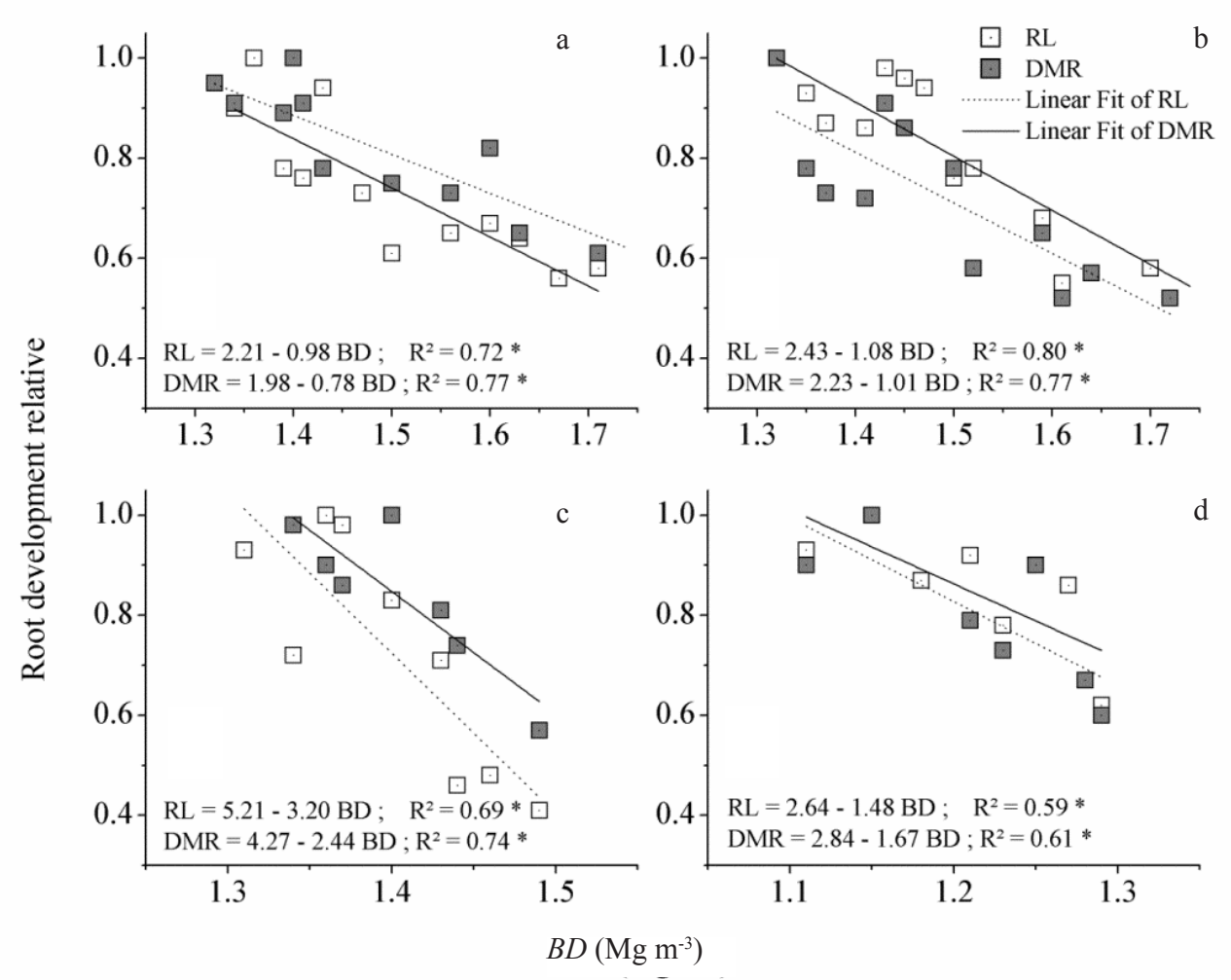

Fig. 3. Effect of soil bulk density $(B D)$ on root length (RL) and dry mass of roots (DMR) of soybean in: $\mathrm{a}-$ sandy loam, $\mathrm{b}$ - sandy clay loam, c - clayey, and d - very clayey soils $(\mathrm{d})$.

sandy clay loam soil (Fig. 2). Corroborating these results, Reichert et al. (2003) proposed intervals for $B D$ for some soil textural classes as 1.30 to $1.40 \mathrm{Mg} \mathrm{m}^{-3}$ for clayey soils, 1.40 to $1.50 \mathrm{Mg} \mathrm{m}^{-3}$ for clay loam, and 1.70 to $1.80 \mathrm{Mg} \mathrm{m}^{-3}$ for the sandy loam.

To evaluate the critical $B D$ for root soybean development, the Q1/2 index suggested by Dexter (1987) was used, which considers soil physical conditions critical when root growth is reduced to half of the maximum. For this, from the equations in Fig. 3, the values of $B D$ in which root growth would be halved were $1.82,1.75,1.51$, and $1.46 \mathrm{Mg}$ $\mathrm{m}^{-3}$ for the sandy loam, sandy clay loam, clayey, and very clayey soils. Therefore, it can be noticed that the highest values of $B D$, defined in the treatments, were not sufficient to halve the RL, when the soil was maintained in the $\theta_{F C}$. In fact, substituting in the adjustment equations (Fig. 3) the $B D$ variable by the $B D$ for 2 and $3 \mathrm{MPa}$, significant $\mathrm{RL}$ reduction was observed only for the sandy loam soil (41 and 49\%), compared to sandy clay loam (19 and 35\%), clayey (11 and 26\%), and very clayey (17 and 6\%) soils, considering the maximum RL.

The dry mass of roots (DMR) was positively related with the dry mass of shoots (DMS). Although this relationship was significant ( $p<0.01$, Fig. 4 ), the low coefficient of determination $\left(\mathrm{R}^{2}\right)$ indicated that the variability in the growth of the above-ground part of plants was possibly influenced by other variables than the root growth variation due the increase in $B D$.

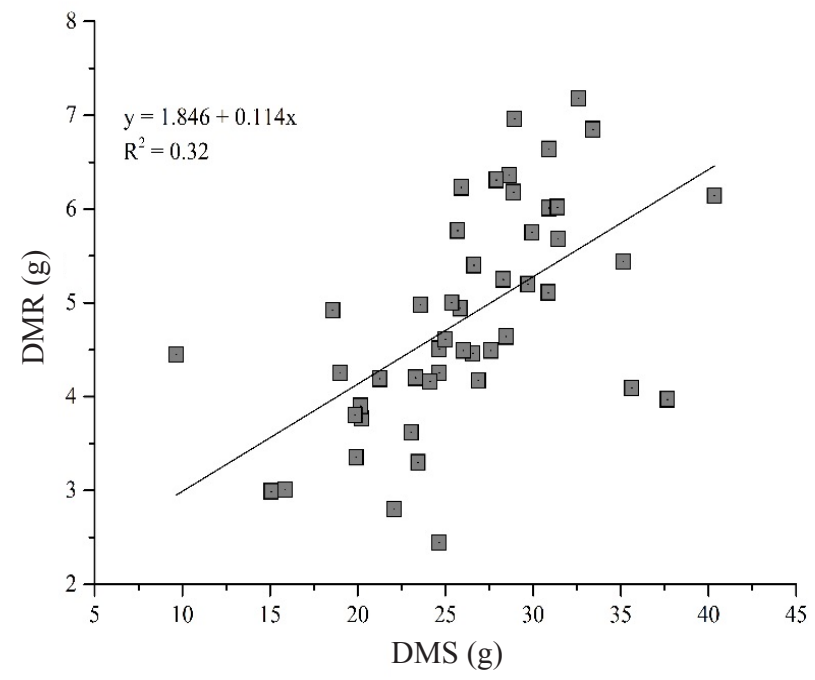

Fig. 4. Relationship between dry mass of roots (DMR) and dry mass of shoots (DMS) considering all soils (sandy loam, sandy clay loam, clayey, and very clayey) and bulk densities (treatments).

The highest values of $B D$ for a $50 \%$ RL reduction, compared to the values of $B D(2$ and $3 \mathrm{MPa})$, indicate that the values of $P R$ adopted as restrictive to plant growth were not sufficient to compromise the development of root soybean when the soil water content was adequate $\left(\theta_{F C}\right)$. This occurs because the suitable supply of water and nutrients in soil minimizes the effect of $P R$ on plant growth (Beutler 
and Centurion, 2003). Dexter (1987) claims that plants can growth normally under conditions of high soil penetration resistance $(P R>4 \mathrm{MPa})$ since there is adequate soil water availability.

Soil bulk density $(B D)$ is considered a soil physical quality indicator and, studying the changes in $P R$ with changes in $B D$ and $\theta$, may help by relating the possible changes in soil physical condition by the adoption of a particular soil management practice, such as the conventional system. The empirical relationship of this simple soil indicator and root soybean development could further be used in monitoring and appropriate management of soil structure and moisture content, for adequate growth and yield in the new cultivated lands in Brazilian Amazon.

In the present paper, the effect of increasing $B D$ and a consequent increase in $P R$ for the soybean root growth was evaluated only in one condition of soil water content, field capacity. However, the results indicated that even when the moisture was adequate, the soil $P R$ reached values considered limiting for the proper plant growth. Hence, after this preliminary study, further research is recommended to evaluate the effect of water stress in this region, since the results of many studies available should not be extended to this region due to differences in climatic conditions.

\section{CONCLUSIONS}

1. At higher bulk densities the increase in soil water content decreases penetration resistance, allowing unrestricted growth of soybean roots.

2. Irrespective of the soil textural class, the penetration resistance of 2 and $3 \mathrm{MPa}$, considered limiting for root growth, had a slight effect on soybean root growth, when soil moisture was maintained at field capacity.

3. Considering the analyzed soil textural classes, even with high soil moisture content, a reduction of $50 \%$ in the soybean root growth was noted at bulk density values of $1.82,1.75,1.51$, and $1.45 \mathrm{Mg} \mathrm{m}^{-3}$ for the sandy loam, sandy clay loam, clayey, and very clayey soil, respectively.

\section{REFERENCES}

Benghough A.G. and Mullins C.E., 1990. Mechanical impedance to root growth: A review of experimental techniques and root growth responses. J. Soil Sci., 41, 341-358.

Beutler A.N. and Centurion J.F., 2003. Effect of water content and soil compaction in soybean production (in Portuguese). Brazilian Agricultural Research, 38, 849-856.

Blake G.R. and Hartge K.H., 1986. Bulk Density. In: Methods of soil analysis: physical and mineralogical methods (Ed. A. Klute). Am. Society of Agronomy, Madison, WI, USA.

Busscher W.J., 1990. Adjustment of flat-tipped penetrometer resistance data to a common water content. Trans. ASAE, $33,519-524$.

Czyż E.A., 2004. Effects of traffic on soil aeration, bulk density and growth of spring barley. Soil Tillage Res., 79, 153-166. da Veiga M., Horn R., Reinert D.J., and Reichert J.M., 2007. Soil compressibility and penetrability of an Oxisol from southern Brazil, as affected by long-term tillage systems. Soil Till. Res., 92, 104-113.

Dexter A.R., 1987. Mechanics of root growth. Plant Soil, 98, 303-312.

Embrapa - Brazilian Agricultural Research Corporation, 2006. Brazilian system of soil classification (in Portuguese). Embrapa Soils, Rio de Janeiro, Brazil.

Embrapa - Brazilian Agricultural Research Corporation, 2010. Fertilization and liming recommendation for the State of Para (in Portuguese). Embrapa Eastern Amazon, Belem, Brazil.

Embrapa - Brazilian Agricultural Research Corporation, 2011. Manual of soil analysis methods (in Portuguese). Embrapa Soils, Rio de Janeiro, Brazil.

Figueiredo G.C., Silva A.P., Tormena C.A., Giarola N.F.B., Moraes S.O., and Almeida B.G., 2011. Improvement of a testing apparatus for dynamometry: procedures for penetrometry and influence of strain rate to quantify the tensile strength of soil aggregates. Brazilian J. Soil Sci., 35, 373-387.

Gee G.W. and Bauder J.W., 1986. Particle size analysis. In: Methods of Soil Analysis: Physical and Mineralogical Methods (Ed. A. Klute). America Society of Agronomy, Madison, WI, USA.

Horn R. and Baumgartl T., 2000. Dynamic properties of soils. In: Handbook of Soil Science (Ed. M.E. Sumner). CRC Press, Boca Raton, FL, USA.

Klute A., 1986 (Ed). Water retention: Laboratory methods. In: Methods of soil analysis: physical and mineralogical methods. America Society of Agronomy, Madison, WI, USA.

Koolen A.J., 1994. Mechanics of soil compaction. In: Soil compaction in crop production (Eds B.D. Soane, C. van Ouwerkerk). Elsevier Sci., Amsterdam, the Netherlands.

Oliveira P.D., Sato M.K., Lima H.V., and Rodrigues S., 2015. Critical limits of the degree of Compactness and soil penetration resistance for the soybean crop in the North of Brazil. J. Plant Nutrition Soil Sci. (in press).

Pabin J., Sienkiewicz J., and Włodek S., 1991. Effect of loosening and compaction on soil physical properties and sugar beet yield. Soil Till. Res., 19, 345-350.

Reichert J.M., Reinert D.J., and Braida J.A., 2003. Soil quality and sustainability of agricultural systems (in Portuguese). Sci. Environ., 27, 29-48.

Reichert J.M., Suzuki L.E.A.S., Reinert D.J., Horn R., and Håkansson I., 2009. Reference bulk density and critical degree-of-compactness for no-till crop production in subtropical highly weathered soils. Soil Till. Res., 102, 242-254.

Rosemberg N.J., 1964. Response of plants to the physical effects of soil compaction. Advances Agronomy, 16, 181-196.

Rosolem C.A., Foloni J.S.S., and Tiritan C.S., 2002. Root growth and nutrient accumulation in cover crops as affected by soil compaction. Soil Till. Res., 65, 109-115.

Seben Júnior G.F., Cora J.E., and Lal R., 2014. Effect of cropping systems in no-till farming on the quality of a Brazilian Oxisol. Brazilian J. Soil Sci., 38, 1268-1280. 
Suzuki L.E.A.S., Reichert J.M., and Reinert D.J., 2013. Degree of compactness, soil physical properties and yield of soybean in six soils under no-tillage. Soil Res., 51, 311-321.

Taylor H.M, Roberson G.M., and Parker J.J., 1966. Soil strength-root penetration relations for medium to coarsetextured soil materials. Soil Sci., 102, 18-22.

Tennant D., 1975. A test of a modified line intersect method of estimating root lenght. J. Appl. Ecol., 13, 995-1001.
Tormena C.A., da Silva A.P., Imhoff S.D.C., and Dexter A.R., 2008. Quantification of the soil physical quality of a tropical oxisol using the S index. Scientia Agricola, 65, 56-60.

Weber R. and Biskupski A., 2008. Effect of penetration resistance, bulk density and moisture content of soil on selected yield components of winter triticale in relation to method of cultivation. Int. Agrophysics, 22, 171-177. 